\title{
A RELAÇÃO COM O SABER EM UMA PERSPECTIVA (AUTO)BIOGRÁFICA NA EDUCAÇÃO FÍSICA ESCOLAR
}

\section{- LUCIANA VENÂNCIO}

Universidade Federal do Ceará

\section{- LUIZ SANCHES NETO}

Universidade Federal do Ceará

As narrativas (auto)biográficas possibilitam compreender escolhas e disposições. Neste artigo, analisamos experiências de aprendizagem com a educação física escolar associadas a processos reflexivos de dois(duas) estagiários(as). iscutir indícios da relação com o saber, a partir das narrativas elaboradas no estágio, e identificar temáticas recorrentes, situadas por reflexões e vivências, em diferentes contextos. A pesquisa foi desenvolvida de modo exploratório na disciplina "Estágio I - observação da realidade", no curso de licenciatura em educação física da Universidade Federal do Ceará, a partir de uma perspectiva baseada em narrativas (auto)biográficas dos(as) participantes. A narrativa foi escolhida como método porque permite aos(às) estudantes explicitar suas emoções, percepções e questões - relacionadas à experiência - para confrontar o mundo vivido. A experiência narrada não descreve o tempo cronológico do estágio nas escolas, de forma linear, mas revela o tempo próprio vivido em diferentes realidades, implica releituras sobre o currículo e reconhece a relação com o saber de cada um(a). As escolhas e trajetórias dos(as) estagiários(as) são singulares, próprias a cada professor(a) em formação inicial e permanente, bem como sua intencionalidade ao agir no mundo.

Palavras-chaves: (Auto)biografias. Narrativas. Currículo. Estágio supervisionado. Relação com o saber.

\section{ABSTRACT RELATIONSHIP TO KNOWLEDGE IN PHYSICAL EDUCATION FROM AN (AUTO)BIOGRAPHICAL PERSPECTIVE}

The (auto)biographical narratives make it possible to understand choices and dispositions. In this article, we analyze learning experiences within school physical education associated with reflective processes by two students during a practicum. To discuss evidence of the relationship to knowledge from the narratives elaborated in the 
practicums and to identify recurrent themes, situated with reflections and experiences in different contexts. The research was developed in an exploratory way during the discipline "Practicum I - observation of the reality" in the physical education teaching certification course at the Federal University of Ceará, from a perspective based on (auto) biographical narratives by the participants. The narrative was chosen as method because it allows the students to explain their emotions, perceptions, and questions - related to experience - to confront the lived world. The narrated experience does not describe the chronological time of the practicum in schools in a linear way, but reveals the time itself lived in different realities. It implies re-reading about the curriculum and recognizes the relationship to knowledge of each one. The students' choices and trajectories are unique, specific to each teacher in initial and permanent formation, as well as their intentionality when acting in the world.

Keywords: (Auto)biographies. Narratives. Curriculum. Practicum. Relationship to knowledge.

\section{RESUMEN LA RELACIÓN CON EL SABER EN UNA PERSPECTIVA (AUTO)BIOGRÁFICA EN EDUCACIÓN FÍSICA ESCOLAR}

Las narrativas (auto)biográficas posibilitan comprender opciones y disposiciones. En este artículo, analizamos experiencias de aprendizaje con la educación física escolar asociadas a procesos reflexivos de dos estudiantes. Discutir indicios de la relación con el saber a partir de las narrativas elaboradas en el practicum e identificar temáticas recurrentes, situadas con reflexiones y vivencias en diferentes contextos. La investigación fue desarrollada de modo exploratorio en la disciplina "Practicum I - observación de la realidad" en el curso de licenciatura en educación física de la Universidad Federal de Ceará, a partir de una perspectiva basada en narrativas (auto) biográficas de los(as) participantes. La narrativa fue escogida como método porque permite a los(as) estudiantes explicitar sus emociones, percepciones y cuestiones - relacionadas a la experiencia - para confrontar al mundo vivido. Resultados: la experiencia narrada no describe el tiempo cronológico del practicum en las escuelas de forma lineal, pero revela el tiempo propio vivido en diferentes realidades, implica relecturas sobre el currículo y reconoce la relación con el saber de cada uno(a). Las trayectorias de los(as) alumnos(as) en prácticas son singulares, propias a cada profesor(a) en formación inicial y permanente, así como su intencionalidad.

Palabras claves: (Auto)biografias. Narrativas. Curriculum. Enseñanza supervisada. Relación con el saber. 


\section{Introdução}

O saber (auto)biográfico está imbricado ao processo histórico da humanidade e da elaboração dos conhecimentos científicos em vários campos. No âmbito da educação física brasileira, tem havido crescente valorização das narrativas como modo de compreensão situada dos contextos educacionais escolares. Desde meados da década de 1980, a aproximação da educação física às ciências humanas tem promovido (auto)crítica acerca do paradigma biológico e ressaltado a complexidade que permeia a dinâmica convergente entre os elementos culturais, os movimentos, os aspectos corporais (inter)pessoais e as demandas ambientais. Essa (auto)crítica tem contribuído para ampliar as possibilidades epistemológicas que emanam do sul, mediante diálogos regionais na América Latina e repercussões no Caribe e Nova Zelândia (OVENS; BUTLER, 2016).

No âmbito latinoamericano, a pesquisa (auto)biográfica na educação física tem evidenciado uma busca pela identidade coletiva da área, bem como pela valorização das trajetórias formativas dos(as) alunos(as) e dos(as) professores(as) como sujeitos de suas próprias experiências (ACOSTA, 2013). Segundo Suárez (2008), a narrativa compartilhada das experiências pedagógicas e das práticas educativas potencializa a (auto)crítica entre os(as) professores(as). Essa perspectiva, de acordo com Santos (2014), implica na valorização dos processos de ensino e de aprendizagem a partir de cada contexto regional, mas também com abertura ao diálogo entre os pares em contextos que, embora diferenciados, podem demandar desafios similares aos processos formativos e, assim, fomentar globalmente a equidade e a justiça social nos currículos. Conforme Ovens e Butler (2016), no Brasil, há - caso dos(as) professores(as)-pesquisadores(as) de educação física escolar que investigam reflexivamente e colaborativamente as suas próprias práticas educativas, a partir de narrativas (auto)biográficas.

Especificamente no contexto brasileiro, a ênfase nas narrativas (auto)biográficas tem permitido aprofundar temáticas complexas e alargar nichos interdisciplinares de saberes no campo educativo. Nesse sentido, a educação física tem incorporado perspectivas que valorizam a subjetividade das vivências, bem como os modos autorais de narrá-las. Esse reencontro consigo mesmo(a) pode contribuir para preencher uma lacuna salientada por Nietzsche (2012) sobre a seriedade das vivências. Há homens e mulheres, sujeitos do conhecimento científico, que desconhecem a si mesmos(as) porque desencontram-se de si para buscar algum tipo de saber desencarnado da vida. Para Nietzsche, precisamos voltar a procurar a nós mesmos(as) para compreender o que foi que vivemos e, para isso, necessitamos reconhecer a urgência do tempo presente, retomando-o e dando ouvidos a nós mesmos(as) para não estarmos ausentes em nossas próprias vivências.

A incorporação de escritos (auto)biográficos contribui para retomar a subjetividade na epistemologia da prática educativa. Contudo, conforme Sanches Neto e Souza Neto (2014), há o risco de cooptação dos(as) professores(as) pelo meio acadêmico à medida que os relatos de suas práticas podem ser utilizados para reforçar aportes teóricos de grupos institucionalizados de pesquisa. É justamente o compartilhamento e a publicização da escrita (auto)biográfica pelos(as) próprios(as) professores(as) que pode reduzir esse risco, sobretudo com a consolidação de coletivos que assumem a centralidade do trabalho docente nas escolas. Borges e Sanches Neto (2014) apontam que perspectivas colaborativas na análise de práticas pedagógicas também podem fomentar o aprofundamento das narrativas entre os(as) professores(as), bem como a sua criticidade, ainda que os seus contex- 
tos regionais de trabalho sejam bastante diferenciados.

A relação com o saber pressupõe a centralidade do sujeito da experiência como sujeito de saberes. Para Charlot (2000) e Venâncio (2014), o afã da comunidade científica por resolver suas questões, seus objetos e seus métodos de pesquisa remete ao esquecimento da necessidade de integração das lógicas próprias que caracterizam cada processo investigativo no campo educativo. É nesse sentido que a condição social humana precisa ser valorizada para circular as diferentes lógicas no ordenamento de pesquisas, de modo que os(as) pesquisadores(as) se interroguem sobre a sua própria relação com o saber. Durante a formação inicial de professores(as), o estágio supervisionado pode ser um "divisor de águas" para esse questionamento na consolidação da identidade docente, fomentando que os(as) professores(as) assumam-se como investigadores(as) de suas práticas educativas (IZA et al, 2014).

A relação com o saber e com o mundo implica no tempo, no lugar e nas pessoas (CHARLOT, 2000). Esse processo introspectivo remete a uma ação de imersão na própria experiência vivida e vívida, que se assemelha ao "nadar" em direção de si mesmo(a) (VENÂNCIO, 2014). Conforme Larrosa Bondía (2002), o saber de experiência é baseado no que nos toca, que nos traz risco e que nos atravessa no tempo vivido da nossa existência. Já o tempo-próprio é aquele continuum vivido pela pessoa singular, que exige reconhecimento de si, enquanto aprende consigo mesmo(a) e com o(a) outro(a). A confluência dessas singularidades, de modo coletivo, implica no compartilhamento das experiências por meio de argumentações situadas que podem assumir várias formas de registro, incluindo as narrativas (auto)biográficas.

As experiências (auto)biográficas no campo da profissão docente ilustram, dentro do universo pedagógico, o amálgama de vonta- des de produzir um outro tipo de conhecimento, mais próximo das realidades educativas e do cotidiano dos professores, valorizando os sujeitos, a qualidade e a vivência em detrimento das estruturas, dos sistemas, da quantidade e do instituído (NÓVOA, 2007). Então, a temática que permeia esse caminho é a da valorização dos(as) professores(as) como quem experimenta o vivido, no cotidiano da prática educativa, e elabora as próprias vivências de forma comunicável para os seus pares. Os principais desafios, nesse âmbito investigativo acerca da educação física, consistem em adentrar os modos de elaboração das reflexões próprias da disciplina, bem como a convergência com outras áreas do conhecimento, em um tipo de narrativa associada à epistemologia da prática educativa (SANCHES NETO; SOUZA NETO, 2014).

O problema, em sintese, remete às duas questões que nos permitiram orientar este estudo: os modos de narrar as experiências vividas permitiram compreender as escolhas e as posições diante do mundo de cada estudante de educação física durante o estágio? Como é ensinar os(as) estudantes a partir dos modos como aprendem com a experiência do estágio? Nossa ênfase recai nos modos de narrar as experiências vividas e também nas escolhas e nos posicionamentos dos(as) estudantes.

De acordo com Neira (2017), as narrativas valorizam os conhecimentos tanto de professores(as) quanto de estudantes da licenciatura em educação física. No âmbito da formação permanente, é importante que os(as) licenciandos(as) beneficiem-se pelos conhecimentos elaborados por professores(as) que já trabalham na educação básica. Porém, como a experiência é própria a cada sujeito, é necessário que os(as) próprios(as) estudantes elaborem seus saberes. Para Neira (2017), as narrativas pessoais são atividades que fomentam a (auto)formação durante o curso de licencia- 
tura e que se assemelham ao registro de relatos de experiência.

As narrativas estimulam a reflexão sobre a própria ação, sobretudo quando são analisadas de modo coletivo por professores(as) em diferentes estágios da carreira docente. No caso da formação inicial, Neira (2017) aponta a ocorrência de discussões sobre situações de aprendizagem, a mobilização de conceitos que fundamentam as intervenções e a análise das experiências individuais. Essas atividades posicionam os(as) estudantes em situações que demandam a reflexão e a busca por alternativas para o encaminhamento de problemas compartilhados entre os(as) colegas.

Assim, partimos da premissa de que os modos de narrar experiências vividas em contextos educacionais possibilita compreender as escolhas e posições de estudantes durante a realização do estágio. Nesse sentido, as experiências de aprendizagem com a educação física escolar são vivenciadas como tempo próprio e situá-las requer rigorosidade reflexiva. Neste artigo, temos dois objetivos. O objetivo geral é discutir indícios da relação com o saber, a partir das narrativas elaboradas no estágio de observação, em todos os segmentos da educação básica durante o 10 semestre de 2017. O objetivo específico é identificar temáticas recorrentes nas narrativas, situadas com reflexões e vivências, em diferentes contextos educacionais.

\section{Percurso e escolhas metodológicas}

A pesquisa tem caráter (auto)biográfico e foi desenvolvida de modo exploratório junto a uma turma de estagiários(as), na disciplina "Estágio supervisionado I - observação e investigação da realidade" do curso de licenciatura em educação física da Universidade Federal do Ceará, a partir de uma perspectiva baseada em narrativas dos(as) quinze partici- pantes da disciplina ${ }^{1}$ e sua relação com o saber. A disciplina abrange $120 \mathrm{~h}$, dentre as quais $80 \mathrm{~h}$ são destinadas às atividades nas escolas. A narrativa foi escolhida como estratégia metodológica, porque permite aos(às) estudantes participantes explicitar suas emoções, percepções e questões - relacionadas à experiência - para confrontar o mundo vivido.

Orientamos a análise segundo dois pressupostos ressaltados por Souza (2004; 2007), a partir de Josso (2004), Nóvoa (2007) e Pineau (2000), sobre a metodologia (auto)biográfica: os princípios da reflexibilidade e da autonomização/emancipação dos sujeitos. Ambos os princípios pressupõem a atividade de pesquisa inerente à (auto)formação docente. Por um lado, mantivemos a preocupação com o processo formativo dos(as) participantes, no sentido de que a sua formação implica a reflexão sobre os próprios percursos de vida. Por outro lado, propusemos a narrativa (auto) biográfica como opção investigativa sobre o processo de formação para, no nosso caso, buscarmos entender as escolhas e disposições dos(as) participantes. Cada narrativa consistiu em uma tentativa de reconstrução do vivido, como uma forma de reaprender sobre si mesmo(a) (RICEUR, 1999). O escopo das narrativas tinha certas premissas para fomentar a reflexão (auto)crítica dos(as) participantes: o que conhecemos no estágio supervisionado? 0 que pode ser investigado a partir do estágio? Qual é a leitura positiva e negativa sobre o estágio em grupo? E sobre a supervisão do estágio na escola e a orientação na universidade? O que as narrativas permitem interpretar sobre as realidades vividas? Quais são as dificuldades e sugestões para redimensionar o processo de formação? Para a discussão das narrativas, foi

1 Agradecemos a todos(as) os(as) estudantes que, além de cursarem a disciplina, também participaram dos dois eixos de pesquisa que subsidiaram a elaboração deste trabalho: o eixo "educação física escolar e relação com o saber" e o eixo "processos (auto)formativos colaborativos em educação física escolar". 
sugerido aos(às) estudantes a elaboração de um mapa conceitual ou quadro síntese (GASPARI et al, 2006). Foi a partir dessa síntese que as categorias temáticas que compõem os nossos resultados emergiram.

Então, o fomento à pesquisa a partir das narrativas implica ênfase sobre a epistemologia da prática profissional, sendo que se trata da viabilidade da pesquisa realizada pelo(a) próprio(a) professor(a), ao longo de seu processo de formação permanente. No nosso caso, desde a formação inicial. Já o princípio da reflexão coaduna-se ao sentido do processo reflexivo realizado pelo(a) professor(a) como pesquisador(a), ao passo que o princípio da autonomia condiz com o sentido de emancipação e o rompimento do individualismo das práticas. A temporalidade do processo reflexivo sobre as experiências a partir das práticas educativas evidencia o lugar do próprio sujeito ao formarse, porque a narrativa implica cada "estudante em formação inicial a entender através da reflexão e conscientização do seu percurso de vida, o seu processo de formação" (SOUZA, 2004, p. 58). Há valorização da (auto)formação no fluxo da experiência com o processo permanente de educação, segundo Souza (2004), ao tratar dos três movimentos da formação explicitados e sistematizados por Pineau (2000) - autoformação, heteroformação e ecoformação - porque é a (auto)formação que potencializa a convergência entre a ação dos(as) outros(as) (heteroformação) e do ambiente (ecoformação).

Assim, as nossas escolhas metodológicas tiveram orientação qualitativa e exploratória com narrativas (auto)biográficas situadas de aprendizagem no âmbito do processo formativo. Consideramos as narrativas (auto)formativas, pois essa foi a característica principal atribuída à elaboração do conjunto de narrativas compartilhado pelos(as) participantes. 0 trabalho investigativo foi realizado com estudantes estagiários(as) no período diurno e noturno, sob a orientação de uma professora-pesquisadora, que é a principal autora deste artigo. Para fomentar o diálogo sobre as narrativas, um professor-pesquisador, que trabalha com a orientação de estágio no mesmo curso de licenciatura, exerceu a função de "colega crítico", no processo de análise, como coautor do artigo. Contudo, o nosso foco nos(as) estagiários(as) já indica um limite à abordagem da problemática, ao desconsiderarmos as narrativas dos(as) professores(as) que supervisionaram os(as) estudantes em seus respectivos contextos. Identificamos dois motivos para essa limitação.

O primeiro motivo foi que, no "Estágio supervionado I", os grupos de estagiários(as) permaneceram aproximadamente $15 \mathrm{~h}$ em cada nível de ensino, sendo que esse período foi vivido em escolas e com professores(as) diferentes. O segundo motivo foi que tanto a professora-pesquisadora quanto o professor-pesquisador, apesar de serem experientes, tinham acabado de assumir as disciplinas de estágio supervisionado na universidade e os contextos educacionais estavam em processo de desvelamento. Os laços e as parcerias para a elaboração de novos saberes com os(as) professores(as) supervisores(as) das escolas estavam em processo de estreitamento. Além disso, as vozes dos(as) próprios(as) estudantes ecoaram com intensidades diferentes na polifonia de vozes em cada grupo.

Para o dimensionamento deste trabalho, especificamente, destacamos as narrativas de um estagiário, estudante do período diurno, e uma estagiária, estudante do noturno. O critério subjacente à escolha de ambos os participantes está na nossa escuta sensivel à intensidade dessas duas vozes, que se destacaram durante o estágio. Ele e ela, intencionalmente, predispuseram-se a analisar e aprofundar as suas narrativas (auto)biográficas a partir do estágio, publicizá-las e tomá-las como ponto de partida para elaborar seus projetos de monografia para 
a conclusão do curso de licenciatura em educação física (COSTA JÚNIOR et al, 2017a; 2017b; MELO et al, 2017). Ambos os participantes elaboraram por escrito seis narrativas cada um(a) durante o semestre letivo e assentiram no aproveitamento dos registros e discussões de suas narrativas no desenvolvimento da pesquisa, optando pelo não anonimato. As temáticas desenvolvidas nas narrativas pelos(as) estudantes foram definidas por eles(as) próprios(as), a partir das situações vividas nos diferentes contextos escolares em que realizaram os estágios: escolas públicas e privadas de todos os segmentos da educação básica (desde a educação infantil até a educação de jovens e adultos), localizadas na cidade de Fortaleza.

Para analisar as temáticas evidenciadas nas narrativas (auto)biográficas, consideramos as possiveis aproximações que implicam o tempo, o local e as pessoas. Esses aspectos são fundamentais para caracterizar os elementos presentes na teoria da relação com o saber em três dimensões: epistemológica, identitária e social (CHARLOT, 2000; VENÂNCIO, 2014). Todo o processo de geração de dados para este estudo está vinculado ao projeto "Educação física escolar: a relação com os saberes de estudantes de Fortaleza", previamente aprovado pelo núcleo de pesquisa do Instituto de Educação Física e Esportes da Universidade Federal do Ceará sob o código NP019. Apresentamos a seguir indícios dos pressupostos que fundamentaram a perspectiva (auto)biográfica nos processos formativos dos(as) estagiários(as) e os resultados a partir de suas narrativas.

\section{Indícios da perspectiva narrativa nos processos (auto)formativos da educação física}

A partir desse momento, vamos nos referir ao estagiário - Kilder - e à estagiária - Fabiana - como os(as) estagiários(as), de modo geral, quando o contexto for de interação com os demais participantes nos seus respectivos grupos. Quando houver a necessidade de situarmos as narrativas de modo individual, explicitaremos o nome do(a) participante.

Acerca do princípio da reflexibilidade, os(as) estagiários(as) aprenderam noções sobre processos reflexivos associados à metodologia (auto)biográfica. De acordo com Craig, You e Oh (2013), as narrativas baseadas em experiências de ensino nas escolas podem ser importantes para provocar avanços no campo da educação física, mediante seis características investigativas: a justificativa para a pesquisa, a pesquisa no meio, a pesquisa nas fronteiras, o conhecimento por meio de relacionamento, o conhecimento por meio de verdade narrativa e a busca do percurso que a história conduz.

Segundo Ovens (2017), o uso de narrativas escritas na educação física pode integrar o método formativo de "trabalho com a memória". Nesse contexto, as narrativas permitem rememorações que podem aprimorar os processos de ensino e de aprendizagem a partir de disposições e de posições baseadas em princípios. Porém, há limites quanto à valorização da docência porque a atividade de pesquisa pode ser supervalorizada. Para Tani (2011), que é pesquisador na área de educação física escolar, a sua própria trajetória na forma de uma narrativa (auto)biográfica subordina os avanços qualitativos do campo profissional à qualificação e ao rigor das pesquisas científicas. Nesse caso, na visão de Tani (2011), a colaboração entre os(as) pesquisadores(as) acadêmicos(as) e os(as) professores(as) deve manter as suas funções distintas.

Todavia, há narrativas que remetem à valorização de investigações ancoradas na experiência cotidiana dos(as) professores(as) para a consolidação de uma "teoria da prática" (BETTI, 1996). Por um lado, a pesquisa subsi- 
diada por narrativas dos(as) professores(as) também avançou sobre os saberes docentes na educação física. Por outro lado, nas investigações sobre as práticas pedagógicas há controvérsia quanto à rigorosidade da análise por professores(as) e especialistas. Alguns estudos baseados em narrativas (auto)biográficas dos(as) professores(as) indicam tensão nas nuanças conceituais e teórico-metodológicas (MOLINA NETO et al, 2009; SILVA; DIEHL, 2010).

Durante o período de realização do estágio, não tivemos qualquer pretensão de tratar exaustivamente da conceituação no campo da pesquisa (auto)biográfica com os(as) estudantes, mas buscamos problematizar as narrativas como possibilidades (auto)formativas. Para isso, alguns trabalhos relacionados à temática subsidiaram as discussões com os(as) estagiários(as) e a compreensão sobre o contexto brasileiro, em três âmbitos: no campo das práticas formativas na educação (BRAGANÇA; MAURÍCIO, 2008), no campo das relações formativas com professores(as) do ensino superior e da educação básica (FIORENTINI, 2009) e no campo da pesquisa em educação física escolar (MOLINA NETO et al, 2009; SILVA; DIEHL, 2010). A ênfase recaiu no terceiro âmbito, especificamente quanto à educação física.

Em primeiro lugar, no campo das práticas de formação em educação, Bragança e Maurício (2008) apresentam uma síntese com concepções sobre as narrativas (auto)biográficas. Há diferenciação entre os desdobramentos metodológicos da história oral, da biografia e da (auto)biografia. Na abordagem (auto) biográfica, por sua vez, Bragança e Maurício (2008) situam uma diversidade de aportes teórico-metodológicos: história de vida, etnobiografia, narrativa de vida, biografia educativa ou narrativa de formação. Além disso, há uma diversidade de procedimentos e técnicas como possibilidades em práticas de investigação e formação: questionário biográfico, trabalho com documentos pessoais, entrevista biográfica, história de vida em grupo, seminários de histórias de vida, história de vida na perspectiva de projeto, memoriais e diários.

Conforme Bragança e Maurício (2008), a (auto)biografia consiste em uma produção escrita do próprio sujeito sobre si, tendo como referência sua trajetória existencial, enfocando a vida de forma ampla, sem abordar fragmentos, mas buscando a expressão do que é essencial da vida. No desenvolvimento dessa perspectiva, há apoio em Nóvoa (2007), destacando que foi no âmbito da discussão sobre a formação permanente de professores(as) que o aporte (auto)biográfico avançou como possibilidade metodológica.

Assim, em segundo lugar, apontamos que essa perspectiva subsidia diferentes áreas da pesquisa educacional. Por exemplo, ao tratar do processo de consolidação de uma comunidade de prática investigativa com professores(as) que trabalham no ensino superior e na educação básica, especificamente com o ensino de matemática, Fiorentini (2009) faz uma narrativa de vida sobre um grupo de professores(as), com riqueza de detalhes sobre os modos de fazer que só cabem a quem é de fato participante do processo coletivo que ora descreve e interpreta.

Em terceiro lugar, no trato das questões pertinentes à educação física escolar, Silva e Diehl (2010) trazem uma experiência metodológica a partir da escolha e do uso de procedimentos da narrativa escrita para a geração de indícios com professores(as) de educação física que trabalham na educação básica. Nesse caso, as narrativas podem criar oportunidades para os(as) professores(as) refletirem sobre as suas ações e aprimorarem o seu trabalho, contribuindo com o seu processo de formação permanente (SILVA; DIEHL, 2010). Assim, o registro torna-se crucial para o aprofundamento do trabalho com as narrativas. 
A documentação narrativa de experiências pedagógicas se inscreve no campo da pesquisa educativa como uma modalidade particular da investigação interpretativa que pretende reconstruir, documentar, questionar e tornar críticos os sentidos e compreensões pedagógicas que os professores constroem, reconstroem e negociam quando escrevem, leem, refletem e conversam entre colegas sobre suas próprias práticas educativas. (SUÁREZ, 2008, p. 112)

Segundo Suárez (2008), as narrativas também podem ser uma estratégia metodológica da pesquisa-ação pedagógica. Para isso, as narrativas deveriam estruturar-se a partir do estabelecimento de relações horizontais em espaços próprios de colaboração entre pesquisadores(as) acadêmicos(as) e professores(as) que narram as suas experiências. Porém, conforme Souza (2004), há poucos estudos sobre a potencialidade das narrativas (auto)biográficas no fluxo temporal da experiência durante a formação inicial.

Todavia, são poucos os trabalhos que, a partir da abordagem biográfica e da utilização das narrativas como perspectiva epistemológica e autoformativa, buscam estudar a formação inicial e o estágio supervisionado, relacionando-os com a fertilidade e potencialidade desta abordagem em projetos específicos de investigação-formação de professores. (SOUZA, 2004, p. 74)

Assim, a nossa intenção foi enfatizar a presença dos(das) estudantes para constituir comunidades de investigação (ou de "atenção mútua") durante o período do estágio e chamar a atenção para novos olhares no processo (auto)formativo.

\section{Temporalidade da experiência na relação com o saber durante o estágio}

Constatamos que a experiência narrada não descreve o tempo cronológico do estágio, nas escolas, de forma linear. Ao invés disso, reve- la o tempo próprio vivido pelos(as) estagiários(as) em diferentes realidades, que implicam releituras do currículo da educação física escolar. A discussão das narrativas, por sua vez, permite valorizar a experiência e reconhecer a relação com o saber de cada um(a). O conjunto das seis narrativas escritas pelos(as) estagiários(as) aponta para um fluxo próprio de relações, baseadas nas vivências e experiências, que se coaduna à perspectiva de temporalidade nas múltiplas relações que podem ser estabelecidas com os saberes (VENÂNCIO, 2017).

Com a revelação do tempo próprio vivido em diferentes realidades, por meio das narrativas, identificamos que as releituras a partir da educação física escolar implicam a valorização da experiência de estar novamente na escola, que é uma nova experiência para os sujeitos (LARROSA BONDÍA, 2002). Então, o reconhecimento das relações com os saberes é diferenciado para professores(as) e estudantes, de acordo com suas disposições específicas como sujeitos epistêmicos, pois têm experiências que engendram diversos saberes (CHARLOT, 2000; FREIRE, 2015). Assim, nas narrativas, há confluência da explicitação de emoções, percepções e questões relacionadas à experiência de cada sujeito para confrontar o mundo vivido.

No âmbito da educação física escolar, Neira (2017) valoriza as narrativas de professores(as) e estudantes para depois chamar a atenção para a epistemologia da prática. Porém, para Sanches Neto e Souza Neto (2014) é a prática educativa que engendra saberes experienciais que podem ser explicitados mediante reflexões sistemáticas e por meio das narrativas. Além disso, para Borges e Sanches Neto (2014) há uma dimensão compartilhada que precisa ser compreendida no processo reflexivo. No caso das narrativas dos(as) estagiários(as), identificamos três indícios de convergência acerca da relação com o saber e cinco temáticas recorrentes, que analisamos a seguir. 


\section{Indícios da relação com o saber} nas narrativas

Nas narrativas escritas pelos(as) estagiários(as) a respeito de suas reflexões sobre todos os segmentos da educação básica, encontramos alguns indícios da relação com o saber. As narrativas foram situadas espontaneamente no processo de aprendizagem próprio a cada estudante, com reminiscências de sua trajetória escolar.

Um dos indícios remete ao espaço-tempo e às dimensões identitária e social da escolarização. O estudante Kilder, do período diurno, por exemplo, realizou estágio na educação infantil e no ensino fundamental I e II junto com um grupo de estagiários(as) em uma escola privada. Ele relata que já conhecia o espaço da escola, pois havia estudado naquela mesma escola, porém de algum modo a escola não era mais "a mesma", pois estar lá novamente implicava uma experiência diferente, ao reconhecer a temporalidade da trajetória como estudante da educação básica e na licenciatura.

No local da quadra em que a professora [...] dava aula, havia um campo de areia no qual, quando eu tinha 12 anos, "jogava bola" no momento do recreio. [...] Passou um filme de que eu também fui daquela idade. o primeiro amor, o primeiro beijo, todos no mesmo local em que pretendo trabalhar, isso de certa forma me motiva a querer sempre a melhor forma de ensinar. Não consigo entrar no Colégio [...] sem, pelo menos, passar em frente às salas que me deram a possibilidade de estar novamente lá de forma diferente. (Excerto narrativo do estudante Kilder, em 8 junho 2017)

O estudante também aponta a expectativa de trabalhar no contexto daquela escola. Além do tempo, aspecto valorizado na relação com o saber, as dimensões identitária e social com o saber convergem em momentos peculiares vividos pelo sujeito. Kilder explicita isso, ao assumir e narrar o desejo de voltar, pois se identifica, tem uma relação (identitária e social) com as pessoas daquele lugar e que de alguma forma influeciaram sua formação. Nesse sentido, outro indício remete à perspectiva de trabalho de cada professor(a), já vislumbrada durante a formação inicial. Como exemplo, a estudante Fabiana, do período noturno, realizou estágio no ensino médio em uma escola pública estadual junto com outro grupo de estagiários(as). Ela reflete sobre a conduta docente de modo a qualificar a complexidade da docência e situar as premissas que subsidiam as estratégias educativas escolhidas pelo professor que supervisiona o seu estágio.

O relato que gostaria de fazer essa semana é sobre algo que me chamou muito a atenção em relação à postura do professor diante dos alunos. o professor [...] leciona à noite e muitos dos alunos trabalham e não se sentem muito dispostos a fazer as aulas práticas. Nas semanas anteriores observei suas aulas teóricas e na última ele comunicou que as aulas práticas começariam. Ele deixou bem claro que os alunos eram livres para não fazerem a aula, não eram obrigados, mas pediu que antes de optarem por não fazer, dessem uma chance a ele participando de, pelo menos, uma aula para saberem como ela se desenvolve. Bem, na quinta-feira que iniciaram as aulas práticas não tive estágio por ter havido aula presencial junto à professora, mas na semana seguinte me deparei com uma aceitação quase que total das turmas nas aulas práticas. Isso me deixou muito feliz. A aula fora muito participativa e vi o entusiasmo dos alunos e a excelente preparação do professor. Acredito que a frase "dê-me uma chance", dita pelo professor, tenha surtido um efeito extremamente positivo e ele soube aproveitar a oportunidade ministrando uma excelente aula que, com certeza, faz com que o aluno sinta-se chamado a sempre participar. (Excerto narrativo da estudante Fabiana, em 25 maio 2017)

Percebe-se nesse excerto narrado por Fabiana, que ela evidencia um desejo de saber 
se os alunos e as alunas do ensino médio se mobilizaram para aprender algo com a educação física após a declaração do professor em reconhecer a condição vivida por seus(suas) alunos(as). $\mathrm{Na}$ perpectiva da relação com $\mathrm{O}$ saber, a preocupação narrada por Fabiana nos leva a compreender como as dimensões epistemológicas e sociais se imbricaram na lógica complexa do ensino percebida por ela na argumentação do professor e na mobilização dos estudantes.

A seguir, é levantada uma questão em outra narrativa de Kilder:

o que uma grávida pode fazer numa prática? No caso, o professor [...] do colégio [...] aplicou uma AP (Avaliação Parcial) prática e uma de suas alunas estava grávida. A AP era um circuito no qual havia local para fazer, prancha, deslocamento lateral, exercício de coordenação, polichinelos, pular corda e mountain clain. Esta aluna passou em todos os locais do circuito. O professor determinou antes da aula começar que ela não participaria de nada. [...] Não sei como lidar, gostaria de referências indicadas pela senhora. (Excerto narrativo do estudante Kilder, em 22 maio 2017)
No excerto narrado acima, há uma preocupação com o próprio saber. Kilder viu-se diante de uma situação que, se estivesse na condição de mediar o processo de escolha da estudante, não saberia se tinha sabedoria suficiente. Nesse sentido, evidencia uma preocupação epistemológica e social com o saber, que implicaria a vida e a conduta tomada por uma outra pessoa.

Tanto Kilder quanto Fabiana e os(as) demais estudantes realizaram os seus estágios em grupos, juntamente com colegas matriculados(as) na disciplina "Estágio I", no período diurno ou noturno. Porém, todos(as) os(as) estagiários(as) elaboraram individualmente as suas narrativas, compartilhando-as semanalmente. Aproveitamos para elucidar, oportunamente, que o procedimento de agrupar os(as) estudantes não foi realizado especificamente para as finalidades desta pesquisa. Todas as etapas dos estágios supervisionados são realizadas em grupos, conforme orientação da comissão de estágio do curso de licenciatura em educação física. A figura a seguir focaliza as observações gerais do grupo de estágio da Fabiana.

Figura 1 - Foco das observações dos(as) participantes no estágio

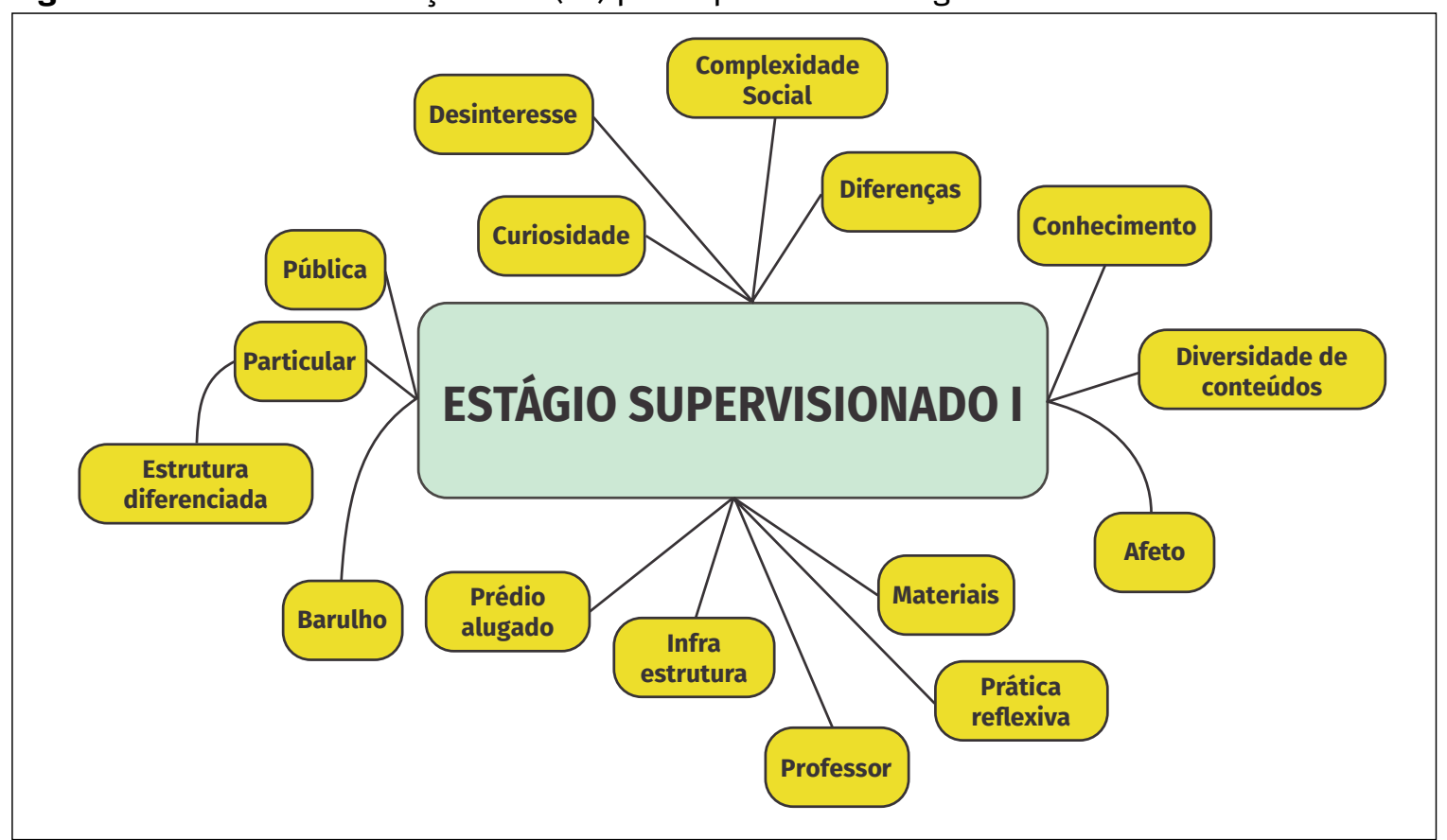

Fonte: Elaboração conjunta dos(as) próprios(as) participantes - grupo da Fabiana. 
Em sintese, os indícios apontam de modo divergente para o tempo-espaço interativo da escola e também para a perspectiva de si acerca de cada professor(a) e estudante. Enleiamse de alguma forma com as dimensões epistemológica, identitária e social da relação com o saber. Contudo, a ênfase na narrativa dos(as) estagiários(as), a partir de suas observações, indica três convergências, que vislumbramos a seguir.

\section{O tempo-espaço interativo da escola}

Os(as) estudantes manifestaram preocupações com aspectos que podem comprometer a interação dos(as) professores(as) com os(as) alunos(as) e entre os(as) alunos(as) na escola. As narrativas de cada contexto incluíram observações sobre a "estrutura diferenciada" das escolas, bem como comparações entre a "escola pública" e a "escola privada". Todavia, a percepção de alguns(as) estudantes não é ingênua, à medida que ressaltaram que a "infraestrutura" aparentemente superior da escola privada dependia de um "prédio alugado", ou seja, a transitoriedade da posse do patrimônio territorial escolar foi percebida como uma das contradições do sistema capitalista.

Cá estou abismado e intrigado com a diferença entre as configurações dos ambientes: escola pública e privada. Não consigo quantificar essa disparidade. Tudo é muito diferente, exatamente, TUDO, inclusive a merenda (risos). Quando minha autobiografia for publicada explicarei que estagiar na mesma escola em que estudou é algo mágico. Esta narrativa foi digitada com sentimentos evocados, especialmente o de NOSTALGIA! (Excerto narrativo do estudante Kilder, em 6 junho 2017)

Além disso, os(as) estagiários notaram que a aprendizagem depende de certa imersão em si, mediante introspecção, e que o "barulho" excessivo restringe essa possibilidade no tem- po-espaço da aula de educação física. Perceberam também que alguns "materiais" podem potencializar o interesse dos(as) alunos(as) durante as vivências, desafiando-os(as) a interagir, de modo que a imersão em si pode ocorrer em vários momentos, mesmo com múltiplas fontes de ruído no ambiente.

A temporalidade é inerente à aprendizagem porque a aprendizagem é um processo que, como qualquer processo, inscreve-se no tempo. Entretanto, a aprendizagem difere de outros processos porque o tempo pedagogicamente necessário à aprendizagem da educação física escolar ultrapassa os limites fragmentados das horas-aulas (VENÂNCIO, 2017). Para Charlot (2000), os(as) alunos(as) podem atribuir sentidos figurativos à aprendizagem (figuras do aprender) e usos variados quando interagem com objetos e realizam atividades. Segundo Venâncio (2017), há um fluxo temporal na relação com o saber a partir das vivências e o acesso a esse fluxo depende da explicitação dos argumentos de cada estudante como sujeito de experiência.

\section{A perspectiva de si para cada professor(a)}

Os(as) estudantes também refletiram sobre a conduta de cada "professor(a) supervisor(a) do estágio", identificando diversas formas de realização da "prática reflexiva" durante as aulas. 0 processo de reflexão foi situado em quatro momentos: antes da intervenção nas turmas, no planejamento das aulas, durante as aulas, com a tomada de decisão por meio do diálogo entre o(a) professor e os(as) alunos(as), após cada aula, com os registros do encontro e uma espécie de meta-análise reflexiva com reflexões sistemáticas sobre as reflexões anteriores (antes, durante e após cada aula).

Ele passou um questionário na lousa, deu uma explicação sobre porcentagem, pois uma das 
questões envolvia isso e logo depois disse que iria dar o visto no caderno e o ponto por participação. A turma que antes estava superexaltada acalmou os ânimos e iniciou a atividade. Tudo corria bem até o professor iniciar o visto nos cadernos. Um dos alunos colocou o caderno em cima da mesa do professor e voltou para sua cadeira onde começou a brincar com outro colega. $O$ professor perguntou de quem era $o$ caderno e ele logo gritou: - É meu! O professor então disse que estava dando o visto de acordo com a chamada, pediu que ele esperasse e que fosse buscar o caderno. $O$ aluno cheio de raiva pegou o caderno e bradou vindo sentar-se em sua cadeira: - Eu odeio esse professor. [...] Eu estava sentada quase ao seu lado e nessa hora ele olhou pra mim e baixou a cabeça e eu não sabia nem como agir diante daquela situação constrangedora. (Excerto narrativo da estudante Fabiana, em 9 junho 2017)

A complexidade do processo reflexivo foi observada pelos(as) estudantes, que associaram o esforço de cada professor(a) ao ensinar com a necessidade de explicitar o seu "afeto" pela turma. A afetuosidade, contudo, não se ateve a uma visão simplista e houve a interpretação de que o "afeto" pode ser tanto positivo quanto negativo e que, por isso, há repercussões diferentes em cada situação de aprendizagem.

De acordo com Charlot (2000), há uma lógica do desejo na relação com o saber que implica uma perspectiva (inter)pessoal, à medida que um sujeito passa a desejar o desejo de outro sujeito. A intervenção dos(as) professores(as), de certo modo, corresponde à lógica do desejo quando os(as) estudantes assumem a perspectiva de si a partir da explicitação das condutas que valorizam nos(as) professores(as) ao longo do estágio.

\section{A perspectiva de si para cada estudante}

Algumas características foram observadas pelos(as) estudantes, no sentido da problema- tização de questões levantadas no curso de licenciatura. Houve discussão de diferentes perspectivas teórico-metodológicas a respeito da "diversidade de conteúdos", pois os(as) professores(as) exploraram várias possibilidades com elementos da cultura de movimento, como a dança e a luta. A "curiosidade" foi potencializada como um aspecto norteador das ações, sendo uma premissa para a intervenção e uma necessidade assumida pelos(as) estagiários(as) para concretizar satisfatoriamente as situações de aprendizagem.

Em contrapartida, a problematização do "desinteresse" dos(as) alunos(as) por alguns conteúdos e por algumas atividades propostas pelos(as) professores(as) foi um desafio para os(as) estagiários(as). Houve proximidade desse problema com a perspectiva dos(as) estudantes, bem como houve a antecipação dessa possibilidade durante as discussões iniciais da disciplina de estágio, com base nas narrativas das trajetórias escolares, antes mesmo da inserção no campo do estágio no contexto das escolas.

A "complexidade social" foi identificada pela multiplicidade de interesses e de preferências dos(as) alunos(as), assim como a aparente contradição com suas condições sociais de origem, tanto na escola pública quanto na escola privada. Conforme Charlot (2000), confrontar a própria condição de origem e mobilizar-se para aprender é uma característica de alunos(as) que conseguem ter êxito na realização do trabalho escolar. Nesse sentido, houve valorização do "conhecimento" como forma de contextualizar as "diferenças" nas situações de aprendizagem, que é um pressuposto da busca por equidade nos percursos (auto)formativos e nas questões curriculares que fomentam a justiça social entre os sujeitos da própria experiência. A seguir um exemplo de uma situação vivida pelo estagiário Kilder, que, apesar de estar 
obrigado a assumir a condução de uma aula, teve a participação influenciada pelas suas características pessoais:

\begin{abstract}
Na primeira turma, primeiro ano $A$, dada minha inquietude, decidi propor uma intervenção. Esta por meio de uma brincadeira bem conhecida, o telefone sem fio. Os alunos mostraram-se motivados quando expliquei o que iria ocorrer. A frase tinha a ver com o conteúdo da aula teórica, envelhecimento, e era: o envelhecimento funcional é mutável. Contudo, a frase chegou na última pessoa totalmente diferente: pacote de pão. Chamei atenção deles para detalhes significativos no processo de ensino-aprendizagem, após o término da brincadeira, meu discurso foi pautado na influência da reprodução do que é visto, ouvido, aprendido, ensinado e etc. Minha intenção foi de intrigá-los e fomentar a criticidade. (Excerto narrativo do estudante Kilder, em 8 maio 2017)
\end{abstract}

Segundo Venâncio (2014), uma situação de aprendizado não é marcada somente pelo local e pela interação com outras pessoas, mas também pelo tempo próprio. Por isso, a aprendizagem implica aprender em algum momento da própria história de vida, que está imbricada a outras histórias diferentes e amplas: da humanidade, da sociedade em que se vive, do espaço no qual se aprende e das pessoas com quem se aprende. Então, “a relação pedagógica é um momento, isto é, um conjunto de percepções, de representações, de projetos atuais que se inscrevem em uma apropriação dos passados individuais e das projeções que cada um constrói - do futuro" (CHARLOT, 2000, p. 68).

Conforme Venâncio (2014, p. 35-36), esse tipo de indício aponta para a "necessidade de ressignificar certas experiências para que façam sentido para os alunos, para que atribuam algum valor às formas educativas escolarizadas com as quais se envolvem e são envolvidos, inclusive na educação física". No contexto do estágio, as narrativas dos(as) estudantes apontaram várias "coisas" que aparentemente só podem ser aprendidas na escola, com os(as) professores(as) e entre os(as) alunos(as). Assim, para Venâncio (2014), a relação com o saber é influenciada pelas dimensões epistemológicas, identitárias e sociais, mas também pelas formas heterogêneas de aprendizagem, que colocam os(as) alunos(as) em confronto com suas necessidades de interação com o mundo. Esse cotejamento ocorre de forma singular para cada sujeito que aprende.

As figuras do aprender extrapolam as convenções dos conteúdos escolares fragmentados disciplinarmente e são definidas por Charlot (2000) como: objetos aos quais algum saber está incorporado (como livros, obras de arte ou programas culturais de TV), objetos cujo uso precisa ser aprendido (como escova de dentes ou computador), atividades que precisam ser dominadas (como ler ou nadar) e dispositivos relacionais, nos quais é necessária a apropriação de algumas formas para o estabelecimento de relações (como agradecer ou começar a namorar). Notamos que as figuras do aprender estão associadas com as temáticas recorrentes nas narrativas dos(as) estagiários(as), como a reminiscência do primeiro beijo pelo estudante Kilder e o dispositivo relacional relatado anteriormente pela estudante Fabiana.

\section{Temáticas recorrentes nas}

\section{narrativas}

As narrativas abrangeram diferentes perspectivas a partir da observação sistemática dos contextos educacionais. Porém, as reflexões dos(as) estagiários(as) com base nas vivências que observaram durante as aulas apontaram certas convergências. Nesse sentido, identificamos cinco temáticas recorrentes em suas narrativas, que remetem à mobilização, reflexão, práticas corporais, elementos da cultura e crise de valores. 


\section{Mobilização para a aprendizagem}

"O que mobiliza os(as) jovens de hoje?" Esse questionamento permeou as reflexões dos(as) estagiários(as) nas discussões sobre as narrativas compartilhadas. Aparentemente, os(as) alunos(as) mobilizaram-se mais intensamente nas situações de aprendizagem em que o ensino apontava para "além do conteúdo". De certo modo, os desejos que se coadunam ao aprender têm alguma semelhança entre os(as) alunos(as) da educação básica e os(as) próprios(as) estagiários(as), pois as narrativas valorizaram a "superação de conceitos tidos como únicos". Isso ocorreu, por exemplo, no caso das vivências propostas pelos(as) professores(as) que não reforçaram ingenuamente os estereótipos (de gênero, midiáticos e de padrões de consumo) associados estritamente aos esportes e buscaram a ampliação do entendimento da diversidade sobre a dança e a luta ao invés do esporte.

Os alunos [...] têm uma ideologia sobre gênero muito encarnada, ou seja, eles não se dão conta do que reproduzem sobre identidade e expressão de gênero, sexo biológico e orientação sexual. Além do mais, o machismo e outros fatores são presentes, com isso, bastou observar a quantidade de meninos e meninas que participaram da aula prática, a diferença é gigantesca. (Excerto narrativo do estudante Kilder, em 2 maio 2017)

Para Kilder, há certa expectativa de que os estereótipos e condutas preconceituosas que percebeu sensivelmente sejam confrontados nas situações de aula pelos(as) professores(as). Segundo Coube e Henriques (2017), há a necessidade de romper com a invisibilidade dos(as) alunos(as), mas esse problema pode ser reforçado por práticas excludentes. Nesse sentido, o tratamento superficial do esporte pode constranger quaisquer praticantes. Assim, as vivências que não reforcem estereótipos podem contribuir decisivamente para que os(as) alunos(as) não permaneçam invisíveis ao seu próprio olhar, bem como ao olhar sensivel do(a) professor(a). Por sua vez, Almeida Júnior (2017) argumenta que as narrativas contribuem para que a formação inicial de professores(as) de educação física seja permeada pela sensibilidade.

\section{Reflexão sobre a realidade}

A "reflexão" foi vislumbrada constantemente como uma "outra forma de olhar a realidade". Desse modo, os(as) estagiários(as) elaboraram argumentos cada vez mais complexos e situados, refutando generalizações durante as discussões, amparados pelas evidências que detalharam em suas narrativas a partir da observação nas escolas. Nesse processo de aprendizagem acerca da própria identidade docente, ao longo do estágio, houve a "desconstrução de uma lógica preconceituosa" sobre, por exemplo, as possibilidades da escola privada em detrimento da escola pública. A valorização da educação pública foi subsidiada por "elementos para uma maior e melhor compreensão da realidade".

Vivenciando o estágio com essas turmas, percebo que as crianças não são insuportáveis, elas só não conhecem limites e com isso acham que podem fazer tudo do jeito que querem, na hora que querem. Mas isso pode ser mudado [...] com políticas públicas e quem mais ganha com isso são as crianças que terão mais oportunidades de serem felizes. (Excerto narrativo da estudante Fabiana, em 18 maio 2017)

De acordo com Iza et al (2014), a identidade docente apresenta múltiplas facetas com destaque para as experiências e trajetórias pessoais e profissionais. Para esses(as) autores(as), a análise das experiências e dos saberes dessas experiências podem ter implicações para a formação de professores(as) de educação física que, não obstante, podem ser tematizadas e aprofundadas nos estágios cur- 
riculares supervisionados. Conforme Contreras Domingo (2016), ancorado em Meirieu (1998), ao explorarmos nossa própria experiência, abrimos caminho para aprender com os mistérios da realidade e refutamos quaisquer expectativas falaciosas de que as outras pessoas e a própria realidade possam ser condicionadas a nosso gosto, pois a realidade sempre nos supera em nossas tentativas de criar as melhores condições possiveis.

\section{Potência educativa das práticas corporais}

Ao assumir para si mesmos(as) a perspectiva de professores(as), houve preocupação dos estagiários(as) com a adequação da sua postura para "ensinar a gostar das práticas corporais". As "práticas corporais" foram analisadas mediante (auto)crítica e os(as) estudantes identificaram que o ensino contextualizado é um desafio, devido à frequência e intensidade de mensagens difusas sobre as práticas corporais, apresentando conceitos superficiais sobre os elementos da cultura e esportivizando todas as práticas (como se jogo, dança, luta, ginástica, circo etc. fossem somente manifestações do "esporte").

[...] foi uma experiência diferente. Os alunos do nono ano fizeram todas as situações com entusiasmo, apesar de ter momentos em que a turma não colaborou na participação. [...] Todos eles se manifestavam positivamente durante a atividade e até mesmo no momento de reflexão [...]. (Excerto narrativo do estudante Kilder, em 3 junho 2017)

Os(as) estudantes apontaram a "força da educação como prática", pois a vivência foi vista como potencializadora da experiência. 0 argumento recorrente foi que a "intervenção como prática" precisa prescindir as discussões, para que os(as) alunos(as) tenham indícios a partir das vivências para fortalecer seu posicionamento, de modo crítico, elaborar os seus próprios conceitos e, caso necessário, confrontar os conceitos apresentados pelo(a) professor(a) e pelos(as) colegas de turma.

Para Almeida Júnior (2017), ancorado na pesquisa de Terra (2010), a formação inicial de professores(as) de educação física pode ser potencializada por estratégias biográficas narrativas, mediante a produção de textos (auto) biográficos que são analisados ao longo da trajetória formativa no curso de licenciatura. No caso dos(as) participantes desta pesquisa, a discussão com os pares fomentou a retomada de vários aspectos incluídos nos escritos, que permeiam a "potencialidade educativa das práticas corporais", durante a realização do estágio.

\section{Cultura corporal do movimento}

Os(as) estudantes identificaram um conjunto de elementos da "cultura corporal de movimento" em suas narrativas, ressaltando a criticidade nos modos de ensino pelos(as) professores(as). Com frequência, a diversidade dos elementos culturais foi o foco das reflexões dos(as) estagiários(as) e ocupou o diálogo sobre o planejamento das aulas. Não obstante, a "cultura corporal de movimento" traz em si uma conotação de convergência entre a "cultura", o "corpo" e o "movimento", que são dinâmicas complexas e têm historicidade, organicidade e intencionalidade em si.

O professor na aula passada havia passado um texto sobre a água e não conseguiu fazer a atividade por conta da indisciplina dos alunos, então essa atividade veio ser feita nessa semana. Ele passou um questionário na lousa, deu uma explicação sobre porcentagem, pois uma das questões envolvia isso e logo depois disse que iria dar o visto no caderno e o ponto por participação. A turma que antes estava superexaltada acalmou os ânimos e iniciou a atividade. (Excerto narrativo da estudante Fabiana, em 9 junho 2017) 
Segundo Sanches Neto et al (2013), o ensino dos elementos culturais (como o jogo, o circo, o esporte, a dança, a ginástica, a capoeira etc.) precisa ser convergente e complexo nas aulas de educação física. Para isso, é necessário associar, nas situações de aprendizagem, temas que dizem respeito à complexidade das demandas ambientais, que abrangem: demandas fisicas e naturais, demandas históricas e geográficas, demandas sociológicas e políticas, demandas estéticas e filosóficas, demandas virtuais, demandas administrativas e econômicas. Os(as) estagiários(as) apontaram aspectos semelhantes, ao referirem-se à "cultura corporal de movimento", em suas narrativas.

\section{Crise de valores}

Por fim, as narrativas apontaram para o "nascimento de um olhar mais cuidadoso" dos(as) estudantes a respeito de uma conduta judicativa. Houve a ampliação do escopo dos olhares para detalhes sobre a interação do(a) professor(a) com cada aluno(a). Todavia, houve a limitação desses olhares pela associação das condutas a pressupostos teóricos que os(as) estagiários(as) já haviam elaborado ao longo do curso quanto à "dimensão atitudinal, conceitual e procedimental" dos conteúdos, vinculada à proposição dos parâmetros curriculares nacionais e da base nacional comum curricular (MALDONADO et al, 2017).

o professor resolveu jogar dessa vez e me chamou bastante atenção a forma como eles agiram com ele nesta aula prática, muito diferente de como o tratam dentro de sala de aula. [...] Em sala o professor assume uma postura mais irritada e na quadra uma mais amena e diverti$\mathrm{da}$, isso interfere diretamente na relação com os alunos. Acredito que o professor necessita rever sua forma de aplicar a aula teórica, já que ela é obrigatória e que infelizmente, por conta da indisciplina dos alunos, acaba por pegar o tempo que era reservado para a prática, mas principalmente os alunos precisam compreender a importância do que está sendo dito em sala e que através de seu bom comportamento e aplicação, a aula termina mais rápido e mais rápido ainda eles estarão em quadra. (Excerto narrativo da estudante Fabiana, em 16 junho 2017)

Os(as) estudantes mencionaram conflitos e alguns limites aos diálogos, quando não ocorria plena participação nas aulas de educação física observada nas escolas. Nesse sentido, demonstraram disposições (auto)críticas acerca do seu próprio posicionamento em um contexto de "crise de valores", questionando-se a si mesmos(as) na perspectiva de professores(as) sobre: "o que o(a) professor(a) propõe" nesses casos? As narrativas reforçaram preocupações dos(as) estagiários(as) com cada aluno(a) - típicas de professores(as) engajados(as) profissionalmente - que indicam que houve o "comprometimento dos(as) estudantes com a aprendizagem em busca de oportunizar mudanças possíveis".

A relevância da temática do ensino de valores no campo da educação física escolar tem sido estudada por Freire, Marques e Miranda (2016), que apontam incertezas a respeito do modo como os valores são ensinados nas aulas. Embora o ensino de valores seja apontado como elemento central ao ensino da educação física, há o risco de assumir expectativas irreais que desconsideram as próprias limitações contextuais da escola e a complexidade envolvida nas premissas judicativas da dimensão atitudinal.

\section{Conclusão}

As escolhas e trajetórias dos(as) estagiários(as) são singulares, próprias a cada professor(a) em formação inicial e permanente. Os percursos identificados nas narrativas de Fabiana e Kilder implicam o desencadeamento de ações intencionais ao agir no mundo. Contudo, esses percursos não se restringem à vinculação com o contexto da escolarização ao longo do está- 
gio. Cada estagiário(a) fomentou a sua individualidade ao refletir sobre a sua experiência. A experiência narrada pelos(as) participantes refere-se ao conjunto de relações com os saberes elaborados além do âmbito da disciplina “Estágio I", mas também a partir da observação rigorosa dos processos de ensino e aprendizagem da educação física escolar.

Consideramos que os modos de aprender e de ensinar a educação física remetem à transição da identidade dos(as) participantes durante o estágio supervisionado, inicialmente vistos por si mesmos como alunos(as), ao assumirem-se reflexivamente como professores(as). Nessa "nova" identidade, marcada pela intencionalidade da própria prática educativa, os dois estudantes escolheram temáticas de pesquisa ancoradas no estágio para a elaboração de seu trabalho monográfico de conclusão de curso (TCC). Além disso, ambos optaram voluntariamente pela participação em um colóquio institucional, sendo que o estudante Kilder também participou de um seminário específico sobre o estágio dos cursos de licenciatura durante os "encontros universitários", que são o principal evento realizado anualmente pela Universidade Federal do Ceará (COSTA JÚNIOR et al, 2017b). Entendemos que essa mobilização dos sujeitos à atividade de pesquisa, fomentada pelas próprias narrativas, é subjacente aos dois princípios (reflexibilidade e autonomização) que orientaram este estudo e que se coadunam à (auto)formação (PINEAU, 2000). Nesse sentido, concluímos que as narrativas contribuem para os processos (auto)formativos dos(as) professores(as) como pesquisadores(as) das próprias práticas educativas (VENÂNCIO et al, 2010; VENÂNCIO, 2012).

A potencialidade das narrativas para a (auto)formação implica também a nós mesmos, como professores(as)-pesquisadores(as), no processo investigativo sobre o curso e sobre o estágio, de modo compartilhado com os(as) estudantes com quem trabalhamos. Essa prática, segundo Souza (2004, p. 154), permite-nos "superar enfoques concernentes à implicação da racionalidade técnica no percurso de formação, no espaço da universidade, configurando-se como modalidade formativa e autoformativa [...] no desenvolvimento do curso e do estágio supervisionado". Para Souza, isso ocorre porque a utilização desse procedimento metodológico (auto)biográfico, por meio das narrativas, favorece os processos reflexivos dos(as) futuros(as) professores(as) sobre as experiências (auto)formadoras em situações concretas da docência. Consequentemente, há "um aprofundamento sobre o conhecimento de si e uma ampliação dos significados da prática didático-pedagógica vivenciada tanto individualmente quanto seus alunos" (SOUZA, 2004, p. 154).

Esperamos que este trabalho também contribua para a compreensão de:

[...] como nos tornamos professores e quais as relações que se estabelecem entre a vivência pessoal - conhecimento de si -, o processo de formação, autoformação e suas implicações para o trabalho docente no campo do estágio supervisionado enquanto uma das instâncias da formação inicial [...] e a adoção da escrita de si como perspectiva epistemológica e metodológica. (SOUZA, 2004, p. 307)

Nesta pesquisa, as narrativas (auto)biográficas reforçaram a reflexão e a autonomia, com sentido emancipatório, de modo que os(as) estagiários(as) se assumiram como sujeitos epistêmicos, o que evidencia um processo (auto) formativo. Acerca das relações com os saberes, Fabiana e Kilder voltaram-se mais para si mesmos [cada um(a) ao seu tempo próprio], e também para os(as) outros(as) (reconhecendo a subjetividade em cada pessoa), bem como identificaram que existem diferentes realidades (situadas em cada local) que precisam 
ser analisadas. Desse modo, tornar-se professor(a) é algo que se (re)faz todo dia diante do mundo, de si e dos(as) alunos(as).

Por isso, concordamos com Molina Neto et al (2009) e com Neira (2017) a respeito da necessidade de valorização das narrativas (auto) biográficas durante o curso de licenciatura em educação física, e de outras áreas que compõem o currículo escolar, mais especificamente, mas não exclusivamente, durante o estágio supervisionado nas escolas. Entretanto, concordamos também com Venâncio (2017) e, por isso, ressaltamos que a (auto)crítica no processo reflexivo de escrita narrativa contribui na formação de professores(as)-pesquisadores para fomentar a relação com o saber, sobretudo acerca da temporalidade no fluxo das experiências narradas.

\section{Referências}

ACOSTA, Fernando. En busca de la identidad de la educación física a través del análisis de las experiencias de estudiantes y egresados del ISEF: una aproximación desde un enfoque narrativo (abordaje metodológico). CONGRESO ARGENTINO DE EDUCACIÓN FÍSICA Y CIENCIAS, 10., set. 2013, La Plata. Anais... La Plata: Facultad de Humanidades y Ciencias de la Educación, Universidad Nacional de la Plata, 2013. Disponivel em: <http://www.memoria. fahce.unlp.edu.ar/trab_eventos/ev.2995/ev.2995. pdf>. Acesso em: 5 jan. 2018.

ALMEIDA JÚNIOR, Admir Soares de. Foto (e) grafias na formação de professores/as de educação física. Revista Brasileira de Pesquisa (Auto)Biográfica, v. 2, n. 6, p. 661-681, set./dez. 2017.

BETTI, Mauro. Por uma teoria da prática. Motus corporis, v. 3, n. 2, p. 73-127, 1996. Disponivel em: <http://citrus.uspnet.usp.br/eef/ephysis/wp-content/uploads/Betti-Mauro-Por-uma-Teoria-da-Prática1.pdf>. Acesso em: 17 maio 2019.

BORGES, Cecília Maria Ferreira; SANCHES NETO, Luiz. Compartilhando a análise de práticas pedagógicas na educação fisica: perspectivas colaborativas. Ins- trumento, v. 16, n. 2, p. 231-248, jul./dez. 2014.

BRAGANÇA, Inês Ferreira de Souza; MAURíCIO, Lúcia Velloso. Histórias de vida e práticas de formação. In: PASSEGGI, Maria da Conceição Ferrer Botelho Sgadari; SOUZA, Eliseu Clementino de. (Orgs.). (Auto) biografia: formação, territórios e saberes. Natal: EDUFRN; São Paulo: Paulus, 2008. p. 253-271.

CHARLOT, Bernard Jean-Jacques. Da relação com o saber: elementos para uma teoria. Porto Alegre: Artmed, 2000.

CONTRERAS DOMINGO, José. Relatos de experiencia, en busca de un saber pedagógico. Revista Brasileira de Pesquisa (Auto)Biográfica, v. 1, n. 1, p. 14-30, jan./abr. 2016.

COSTA JÚNIOR, Mairam Kilder de Lima; VENÂNCIO, Luciana; SANCHES NETO, Luiz. Narrativas autorais: uma estratégia significativa para o estágio supervisionado em licenciatura em educação física. (Webpôster). In: CONGRESSO DOS PROFESSORES DE EDUCAÇÃO FíSICA, 7., 2017a, São Paulo. Anais... São Paulo: Universidade Cidade de São Paulo, 2017a. Disponivel em: <https://www.youtube.com/watch?$\mathrm{v}=6 \mathrm{krnXOolQJ8>}$. Acesso em: 20 fev. 2018.

COSTA JÚNIOR, Mairam Kilder de Lima; VENÂNCIO, Luciana. As narrativas de aprendizagem: modo significativo para vivenciar o estágio supervisionado na licenciatura em educação fisica. Anais... I ENCONTRO DE ESTÁGIOS, Encontros Universitários da UFC, v. 2, n. 1, p. 4110, 2017b. Disponivel em: <http://www. periodicos.ufc.br/eu/article/view/29134/64887>. Acesso em: 17 maio 2019.

COUBE, Roberta Jardim; HENRIQUES, Eda Maria de Oliveira. Imagens dos corpos inscritas nas narrativas de alunos do ensino médio: as (inter)corporeidades e o currículo. Revista Brasileira de Pesquisa Auto(Biográfica), v. 2, n. 6, p. 520-534, set./dez. 2017.

CRAIG, Cheryl J.; YOU, JeongAe; OH, Suhak. Collaborative curriculum making in the physical education vein: a narrative inquiry of space, activity and relationship. Journal of Curriculum Studies, v. 45, n. 2, p. 169-197, 2013. DOI: 10.1080/00220272.2012.732118

FIORENTINI, Dario. Quando acadêmicos da universidade e professores da escola básica constituem 
uma comunidade de prática reflexiva e investigativa. In: FIORENTINI, Dario; GRANDO, Regina Célia; MISKULIN, Rosana Giaretta Sguerra. (Orgs.). Práticas de formação e de pesquisa de professores que ensinam matemática. v. 1. Campinas, SP: Mercado de Letras, 2009. p. 233-255.

FREIRE, Paulo Reglus Neves. Extensão ou comunicação. 17. ed. São Paulo: Paz e Terra, 2015.

FREIRE, Elisabete dos Santos; MARQUES, Bruna Gabriela; MIRANDA, Maria Luiza de Jesus. Teaching values in physical education classes: the perception of Brazilian teachers. Sport, Education and Society, p. 1-13, 2016. DOI: 10.1080/13573322.2016.1213715

GASPARI, Telma Cristiane; SOUZA JÚNIOR, Osmar; MACIEL, Valéria; IMPOLCETTO, Fernanda Moreto; VENÂNCIO, Luciana; ROSÁRIO, Luis Fernando; IÓRIO, Laércio Schwantes; THOMMAZO, Aline di; DARIDO, Suraya Cristina. A realidade dos professores de educação física na escola: suas dificuldades e sugestões. Revista Mineira de Educação Física, v. 14, n. 1, p. 109-137, 2006.

IZA, Dijnane Fernanda Vedovatto; BENITES, Larissa Cerignoni; SANCHES NETO, Luiz; CYRINO, Marina; ANANIAS, Elisangela Venâncio; ARNOSTI, Rebeca Possobom; SOUZA NETO, Samuel de. Identidade docente: as várias faces da constituição do ser professor. Revista Eletrônica de Educação, v. 8, n. 2, p. 273-292, 2014.

JOSSO, Marie-Christine. Experiências de vida e formação. São Paulo: Cortez, 2004.

LARROSA BONDÍA, Jorge. Notas sobre a experiência e o saber de experiência. Revista Brasileira de Educação, n. 19, p. 20-28, jan./abr. 2002.

MALDONADO, Daniel Teixeira; JESUS, Felipe de Souza; FREIRE, Elisabete dos Santos; SANCHES NETO, Luiz. A brincadeira e o jogo no currículo da educação física: a concepção apresentada na versão preliminar da base nacional comum curricular. Licere, v. 20, n. 4, p. 152-185, dez. 2017.

MEIRIEU, Philippe. Frankenstein educador. Barcelona: Laertes, 1998.

MELO, Fabiana Lima da Silveira; FERREIRA, Emma- nuelle Cynthia da Silva; SALES, Francisco Elizeu Soares; SANCHES NETO, Luiz. Perspectivas da educação física na educação infantil a partir da base nacional comum curricular (BNCC): houve avanço em relação ao referencial curricular nacional (RCN)? (Webpôster). In: CONGRESSO DOS PROFESSORES DE EDUCAÇÃO FÍSICA, 7., 2017, São Paulo. Anais... São Paulo: Universidade Cidade de São Paulo, 2017. Disponível em: <https://www.youtube.com/watch?time_continue=1\&v=hvlbBdVyDFw>. Acesso em: 20 fev. 2018.

MOLINA NETO, Vicente; BOSSLE, Fabiano; SILVA, Lisandra de Oliveira e.; SANCHOTENE, Mônica Urroz. Quem aprende? Pesquisa e formação em educação física escolar. Ijuí, RS: Unijuí, 2009.

NEIRA, Marcos Garcia. Análise e produção de relatos de experiência da educação física cultural: uma alternativa para a formação de professores. In: FUNDAÇÃO CARLOS CHAGAS. (Org.). Prêmio Rubens Murillo Marques: experiências docentes em licenciaturas. v. 53. São Paulo: Fundação Carlos Chagas, 2017. p. 53-103.

NÓVOA, António. (Org.). Vidas de professores. 2. ed. Porto: Porto Editora, 2007.

OVENS, Alan. Considering the role of dispositions in learning to teach HPE. In: SANCHES NETO, Luiz; OKIMURA-KERR, Tiemi; VENÂNCIO, Luciana; FREIRE, Elisabete dos Santos. (Orgs.). v. 25. Educação física escolar: diferentes olhares para os processos formativos. Curitiba: CRV, 2017. p. 13-32.

OVENS, Alan; BUTLER, Joy. Complexity, curriculum, and the design of learning systems. In: ENNIS, Catherine D. (Org.). Routledge handbook of physical education pedagogies. New York: Routledge, 2016. p. 97-111.

PINEAU, Gaston. Temporalités en formation: vers de nouveaux synchroniseurs. Paris: Anthropos, 2000.

RICEUR, Paul. Historia y narratividad. Barcelona: Paidós, 1999.

SANCHES NETO, Luiz; SOUZA NETO, Samuel de. A epistemologia da prática e a sistematização de saberes docentes na educação física: a perspectiva de um grupo autônomo de "professores-pesquisadores". Instrumento, v. 16, n. 2, p. 205-220, jul./dez. 2014. 
SANCHES NETO, Luiz; CONCEIÇÃO, Willian Lazaretti da.; OKIMURA-KERR, Tiemi; VENÂNCIO, Luciana; VOGEL, Audrei Juliana Zeferino; FRANÇA, André Luiz de.; CORSINO, Luciano Nascimento; RODRIGUES, Jéssica Camila Ramos; FREITAS, Tatiana Pereira de. Demandas ambientais na educação física escolar: perspectivas de adaptação e de transformação. Movimento, v. 19, n. 4, p. 309-330, out./dez. 2013.

SANTOS, Boaventura de Sousa. Epistemologies of the south: justice against epistemicide. New York: Routledge, 2014.

SILVA, Lisandra de Oliveira e.; DIEHL, Vera Regina Oliveira. Da construção dos procedimentos metodológicos à produção de conhecimentos: compartilhando experiências a partir da narrativa escrita. In: MOLINA NETO, Vicente; BOSSLE, Fabiano. (Orgs.). 0 oficio de ensinar e pesquisar na educação física escolar. Porto Alegre: Sulina, 2010. p. 94-122.

SOUZA, Elizeu Clementino de. 0 conhecimento de si: narrativas do itinerário escolar e formação de professores. 344 f. Tese (Doutorado em Educação) - Programa de Pós-Graduação em Educação, Faculdade de Educação, Universidade Federal da Bahia, Salvador, 2004.

SOUZA, Elizeu Clementino de. (Auto)biografia, histórias de vida e práticas de formação. In: NASCIMENTO, Antonio Dias; HETKOWSKI, Tânia Maria. (Orgs.). Memória e formação de professores. Salvador: EDUFBA, 2007. p. 59-74.

NIETZSCHE, Friedrich Wilhelm. A gaia ciência. São Paulo: Companhia das Letras, 2012.

SUÁREZ, Daniel Hugo. A documentação narrativa de experiências pedagógicas como estratégias de pesquisa-ação-formação de docentes. In: PASSEGGI, Maria da Conceição Ferrer Botelho Sgadari; BARBOSA, Tatyana Mabel Nobre. (Orgs.). Narrativas de formação e saberes biográficos. Natal: EDUFRN; São Paulo: Paulus, 2008. p. 112-121.

TANI, Go. Leituras em educação física: retratos de uma jornada. São Paulo: Phorte, 2011.

TERRA, Dinah Vasconcelos. A biografia-narrativa como estratégia de formação do professor de edu- cação física. In: DALBEN, Ângela Imaculada Loureiro de Freitas; PEREIRA, Júlio Emílio Diniz; LEAL, Leiva de Figueiredo Viana; SANTOS, Lucíola Licínio de Castro Paixão. (Orgs.). Convergências e tensões no campo da formação e do trabalho docente. Belo Horizonte: Autêntica, 2010. p. 352-362.

VENÂNCIO, Luciana. O que nós sabemos? Da relação com o saber na e com a educação física em um processo educacional-escolar. $294 \mathrm{f}$. Tese (Doutorado em Educação) - Programa de Pós-Graduação em Educação, Faculdade de Ciências e Tecnologia, Universidade Estadual Paulista, Presidente Prudente, SP, 2014.

VENÂNCIO, Luciana. Narrative of experience from school physical education: the case of a Brazilian woman. In: MENJA, Juanjo; GARCÍA-VALCÁRCEL, Ana; PEÑALVO, Francisco José García; DEL POZO, Marta Martín. (Orgs.). Search and research: teacher education for contemporary contexts. Salamanca: Aquilafuente, 2017. p. 419-427.

VENÂNCIO, Luciana; MATIAS, Rosangela Aparecida; CORSINO, Luciano Nascimento; ULASOWICZ, Carla; SANCHES NETO, Luiz. Formação Inicial e permanente em educação física: uma experiência com professores-pesquisadores a partir da pesquisa-ação. In: CONGRESSO INTERNACIONAL DE PESQUISA (AUTO) BIOGRÁFICA (CIPA) - Espaço (auto)biográfico: artes de viver, conhecer e formar, 4., 2010, São Paulo. Anais... São Paulo: Universidade de São Paulo, 2010. CD-ROM.

VENÂNCIO, Luciana. Crítica e autocrítica de uma professora-pesquisadora em educação física a partir da narrativa da própria prática de ensinar e aprender. In: TOMMASIELLO, Maria Guiomar Carneiro; MARIN, Alda Junqueira; PIMENTA, Selma Garrido; CARVALHO, Luiz Marcelo; FUSARI, José Cerchi. (Orgs.).

Didática e práticas de ensino na realidade escolar contemporânea: constatações, análises e proposições. v. 3. Araraquara, SP: Junqueira \& Marin, 2012. p. 1-12.

Recebido em: 10/01/2018 Aprovado em: 30/03/2019 
Luciana Venâncio é Doutora em Educação, pela Universidade Estadual Paulista, campus de Presidente Prudente-SP. Pós-doutora em Educação, pela Universidade Federal de Sergipe. Professora Adjunta no Instituto de Educação Física e Esportes da Universidade Federal do Ceará (IEFEs-UFC). e-mail: luciana_venancio@yahoo.com.br

Endereço: Rua Thomaz Pompeu, 340 apto. 2101 - Meireles - Fortaleza, CE CEP: 60160-080 Brasil. Telefones: (11) 972874034 / (85) 3093-6130

Luiz Sanches Neto é Doutor em Pedagogia da Motricidade Humana e Pós-doutor em Educação, pela Universidade Estadual Paulista, campus de Rio Claro-SP. Professor Adjunto do Instituto de Educação Física e Esportes da Universidade Federal do Ceará (IEFEs-UFC). e-mail: luizitosanches@yahoo.com

Endereço: Rua Thomaz Pompeu, 340 apto. 2101 - Meireles - Fortaleza, CE CEP: 60160-080 Brasil. Telefones: (11) 992929539 / (85) 3093-6130 